\section{(6) OPEN ACCESS}

\title{
Effects of a 20-month cluster randomised controlled school-based intervention trial on BMI of school-aged boys and girls: the HEIA study
}

\author{
May Grydeland, ${ }^{1,2}$ Mona Bjelland, ${ }^{2}$ Sigmund Alfred Anderssen, ${ }^{1}$ Knut-Inge Klepp, ${ }^{2}$ \\ Ingunn Holden Bergh, ${ }^{3}$ Lene Frost Andersen, ${ }^{2}$ Yngvar Ommundsen, ${ }^{3}$ Nanna Lien ${ }^{2}$
}

\begin{abstract}
${ }^{1}$ Department of Sports Medicine, Norwegian School of Sport Sciences, Oslo, Norway ${ }^{2}$ Department of Nutrition, Faculty of Medicine, University of Oslo, Oslo, Norway ${ }^{3}$ Department of Coaching and Psychology, Norwegian School of Sport Sciences, Oslo, Norway
\end{abstract}

\section{Correspondence to} May Grydeland, Department of Sports Medicine, Norwegian School of Sport Sciences, PB 4014 Ullevaal Stadion NO-0806, Oslo 0806, Norway; may.grydeland@nih.no

Accepted 29 March 2013 Published Online First 27 April 2013

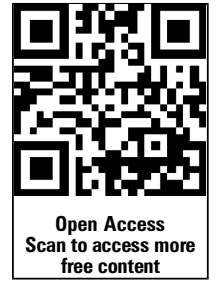

To cite: Grydeland $M$, Bjelland $M$, Anderssen SA, et al. Br J Sports Med 2014;48:768-773

\section{ABSTRACT}

Background School-based interventions that target prevention of overweight and obesity in children have been tested with mixed results. Thus, successful interventions are still called for. The aim of the present study was to investigate effects of a multicomponent school-based intervention programme targeting physical activity, sedentary and dietary behaviours on anthropometric outcomes.

Methods A 20-month intervention was evaluated in a cluster randomised, controlled study of 1324 11-yearolds. Outcome variables were body mass index (BMI), BMI-for-age z-score (BMIz), waist circumference (WC), waist-to-height ratio (WTHR) and weight status (International Obesity Task Force's cut-offs). Weight height and WC were measured objectively; pubertal status was self-reported and parental education was self-reported by the parents. Intervention effects were determined by one-way analysis of covariance and logistic regression, after checking for clustering effects of school, and moderating effects of gender, pubertal status and parental education.

Results Beneficial effects were found for BMI ( $p=0.02$ ) and BMIz $(p=0.003)$ in girls, but not in boys. While a beneficial effect was found for BMI $(p=0.03)$ in participants of parents reporting a high level of education, a negative effect was found for WTHR in participants with parents reporting a low level of education ( $p=0.003)$. There were no intervention effects for WC and weight status.

Conclusions A multicomponent 20-month schoolbased intervention had a beneficial effect on BMI and BMIz in adolescent girls, but not in boys. Furthermore, children of higher educated parents seemed to benefit more from the intervention, and this needs attention in future interventions to avoid further increase in social inequalities in overweight and obesity.

\section{BACKGROUND}

The increasing rates of overweight and obesity in children and adolescents have resulted in several initiatives aiming to prevent further development of the epidemic. School-based interventions targeting prevention of overweight and obesity in children have yielded mixed results. ${ }^{1}{ }^{2}$ However, evidence supports beneficial effects of child obesity prevention programmes on body mass index (BMI) in systematically developed interventions that promote healthy eating and physical activity and emphasise support from teachers and parents and home activities. ${ }^{1}$
A recent systematic review and meta-analysis of controlled trials of objectively measured physical activity concluded that successful physical activity interventions have only had a small effect on children's overall activity levels, ${ }^{3}$ which may partly explain why they have had limited success in preventing childhood obesity. Methodological shortcomings have also been used as an explanation for the lack of intervention effects. ${ }^{2}$ Many intervention studies are underpowered to detect small differences between groups, particularly on adiposity outcomes. ${ }^{1}$ Longer term programmes and comprehensive school-based interventions may be more effective than shorter programmes. ${ }^{4-6}$ There is ongoing discussion regarding the optimal measure of adiposity in larger studies of children and adolescents. Some authors claim that BMI-for-age z-score (BMIz) is the best measure as it adjusts for the age and gender of the child ${ }^{7}$ while others claim that BMI most aptly represents a child's adiposity. ${ }^{8}{ }^{9} \mathrm{BMI}$ and $\mathrm{BMIz}$ are merely estimates of body fatness as these indices do not differentiate between the types of tissue that contribute to body weight (fat, muscle or bone mass).

To determine whether a school-based intervention is truly an effective means to reduce body fat, it may be necessary to assess it using a number of different anthropometric variables. ${ }^{4}$ Questions have also been raised about intervention reach. ${ }^{2}$ Gender and socioeconomic status may moderate intervention effects. ${ }^{10}$ There are still relatively few methodologically strong trials aimed at the primary prevention of weight gain in older children, thus indicating a need to strengthen the evidence base. ${ }^{6} 1112$

Previous results from the HEalth in Adolescents (HEIA) study have shown intervention effects both in psychological and social-environmental determinants of physical activity ${ }^{13}$ and in targeted behaviours like time spent watching TV/DVD, computer/game use, consumption of sugar-sweetened beverages ${ }^{14}$ and physical activity ${ }^{15}$ in either the total sample or the subgroups.

Therefore, we address the following primary objective: to investigate the effects of a systematically developed, 20-month multicomponent school-based intervention programme, the HEIA study, on BMI.

Our secondary objectives were to investigate whether the effect of the intervention on anthropometry was influenced by gender, pubertal status or level of parental education.

\section{METHODS}

The HEIA study was based on a socioecological framework and the intervention was designed so that it was 
feasible to implement and of low cost so that it could be sustained in the public school system. The design and procedures of the HEIA study are thoroughly described elsewhere. ${ }^{16}$ The CONSORT Statement for reporting a randomised trial was followed according to applicability (http://www.consort-statement.org).

\section{Study design and participants}

Eligible schools were those with more than 40 students in the sixth grade and located in the largest towns/municipalities in seven counties in south-eastern Norway. Of the 177 schools invited, 37 agreed to participate (figure 1). All sixth graders in these 37 schools $(n=2165)$ were invited to participate. Of these, $1580(73 \%)$ children returned a parent-signed informed consent form. Twelve schools were randomly assigned by blind draw with all investigators present to the intervention group $(n=784$ children) and 25 schools to the control group $(n=1381$ children). Neither participants nor investigators were blinded for condition.

The data collections took place at each school in September 2007 (baseline) and in May 2009 (postintervention). Anthropometrics were measured by trained staff, and participants filled in a short-paper questionnaire about pubertal status; 1376 children ( $87 \%$ of those returning consent) provided data at baseline and 1361 children at postintervention. A total of 1324 children provided data at both time points which constitute the analysed sample in this paper. A priori, per protocol and drop-out analyses were chosen over intention-to-treat. ${ }^{17}$ Power calculations were based on changes in BMI. Taking the cluster effect of randomly assigning schools to intervention and control into account, assuming that $80 \%$ of the students would participate and that the attrition rate would not exceed $15 \% /$ year, we aimed for 40 schools (10 intervention and 30 control) with an average of 45 students participating from each school. According to these assumptions, we calculated that we should be able to detect a difference between intervention and control schools after 2 years of $0.72 \mathrm{~kg} / \mathrm{m}^{2}$ in BMI. ${ }^{16}$

Ethical approval and research clearance were obtained from the Regional Committees for Medical Research Ethics in Norway and from the Norwegian Social Science Data Service.

\section{Intervention}

The multilevel approach included collaboration with school principals and teachers, school-health services and parent committees. Multiple intervention efforts were orchestrated to promote a healthy diet and to increase awareness of healthy choices, to increase participants' physical activity during school hours and leisure time, and to reduce screen-time. Schoolteachers were the key-persons to implement the intervention components. The main ones are outlined in table 1 and further described elsewhere. ${ }^{16}$

\section{Anthropometric outcomes}

A trained staff person of the same sex as the study participant conducted the anthropometry. Participants wore light clothing or underwear only during these assessments. Height was measured to the nearest $0.1 \mathrm{~cm}$ by a wall-mounted measurement tape with the participant standing upright against the wall. Weight was measured to the nearest $0.1 \mathrm{~kg}$ by a digital scale/ body composition analyser (Tanita TBF-300; Tanita Corp., Illinois, USA). Waist circumference (WC) was measured to the nearest $0.1 \mathrm{~cm}$ by a measuring tape between the lower rib and the iliac-crest at the end of a normal expiration. BMI was calculated $\left(\mathrm{kg} / \mathrm{m}^{2}\right)$. BMI-for-age and sex z-score (BMIz) was calculated by adapting syntaxes for SPSS provided by WHO. ${ }^{19}$ The age-specific and gender-specific BMI cut-off values proposed by the International Obesity Task Force were used to categorise the children as being of normal weight or overweight/obese. ${ }^{20}$ Only $1.8 \%$ of the participants at baseline were obese and thus included with those overweight in the analyses. Waist-to-height ratio (WTHR) was calculated as the ratio of waist $(\mathrm{cm})$ to height $(\mathrm{cm})$.

For ethical reasons, children were asked to self-report their pubertal status by a separate and sex-specific paper questionnaire at the end of the data collection. The questionnaire was based on the Pubertal Category Scores. ${ }^{21}$ The children were categorised into five puberty categories which were collapsed to three because of low numbers in the latter two categories $(3.5 \%$ of the participants in total): prepubertal, early-pubertal, midpubertal/late-pubertal/postpubertal. A reliability study of the anthropometric measures was conducted prior to the survey
Figure 1 Flow diagram of recruitment, randomisation and participation of children in the HEalth in Adolescents study. *Percentage of participants with consent.

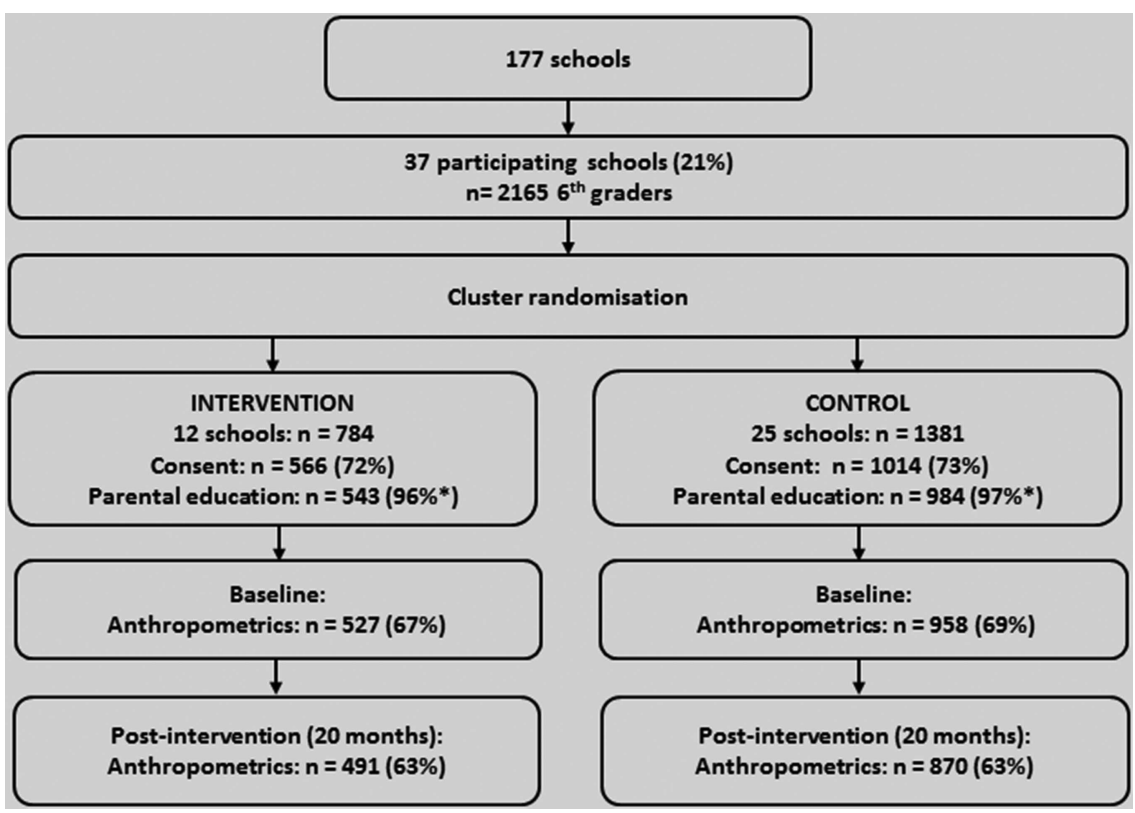


Table 1 The HEIA study: intervention components implemented in the sixth and seventh grades in 12 Norwegian schools in 2007/2008 and 2008/2009

\begin{tabular}{|c|c|c|c|}
\hline Setting/arena & What & Timing & Purpose \\
\hline \multirow[t]{8}{*}{$\begin{array}{l}\text { Class (initiated by } \\
\text { classroom-teachers) }\end{array}$} & $\begin{array}{l}\text { Lessons with student booklet: } \\
\text { 1. Diet and physical activity } \\
\text { 2. Meals } \\
\text { 3. } 5 \text { a day } \\
\text { 4. Sugar-rich beverages } \\
\text { 5. Your choice }\end{array}$ & $\begin{array}{l}\text { Once a month-6th grade } \\
\text { winter/spring }\end{array}$ & $\begin{array}{l}\text { Increase awareness of behaviour-health relationship, } \\
\text { recommended intake levels and own intake }\end{array}$ \\
\hline & $\begin{array}{l}\text { Posters for classrooms: } \\
\text { Key messages, A4-size, placed on a larger } \\
\text { 'frame-poster' including the HEIA logo }\end{array}$ & $\begin{array}{l}\text { Monthly-throughout the } \\
\text { intervention }\end{array}$ & $\begin{array}{l}\text { As a daily reminder of main messages (topic matched fact } \\
\text { sheets to parents) }\end{array}$ \\
\hline & $\begin{array}{l}\text { Fruit and vegetable (FV) break: } \\
\text { Cutting equipment per class provided, } \\
\text { students brought FV }\end{array}$ & $\begin{array}{l}\text { Once a week-throughout the } \\
\text { intervention }\end{array}$ & Increase FV intake; cut, serve, taste and eat FV with classmates \\
\hline & $\begin{array}{l}\text { Physical activity (PA) break: } \\
10 \text { min of PA conducted in regular classrooms, } \\
\text { booklet with ideas and CD provided }\end{array}$ & $\begin{array}{l}\text { Once a week-throughout } \\
\text { the intervention }\end{array}$ & $\begin{array}{l}\text { Increase PA; introduce PA also outside of PE and by } \\
\text { classroom-teachers }\end{array}$ \\
\hline & $\begin{array}{l}\text { Sports equipment for recess activities: } \\
1-2 \text { large boxes per school. Examples of } \\
\text { content: Frisbees, jump-ropes, elastic bands, } \\
\text { hockey-sticks, a variety of balls }\end{array}$ & $\begin{array}{l}\text { Every day-throughout the } \\
\text { intervention (some refill in } \\
\text { seventh grade) }\end{array}$ & $\begin{array}{l}\text { Increase PA; stimulate PA during recess-especially among } \\
\text { those who do not play ball games }\end{array}$ \\
\hline & $\begin{array}{l}\text { Active commuting campaigns: } \\
\text { Register days with active transport to/from } \\
\text { school for } 3 \text { weeks ( } 5 \text { campaigns) }\end{array}$ & $\begin{array}{l}5 \times 3 \text { weeks: sixth grade: fall, } \\
\text { winter and spring } \\
\text { seventh grade: fall, winter }\end{array}$ & Increase PA; stimulate activity \\
\hline & $\begin{array}{l}\text { Pedometer: } \\
\text { One class-set per school to be used in PE } \\
\text { (SPARK), as tasks at school, as home } \\
\text { assignment and active commuting }\end{array}$ & Seventh grade & Increase awareness about PA level; stimulate activity \\
\hline & $\begin{array}{l}\text { Computer tailored individual advice } \\
\text { 1. Fruit } \\
\text { 2. Vegetables } \\
\text { 3. Physical activity } \\
\text { 4. Screen time } \\
\text { 5. Sugar sweetened beverages } \\
+1 \text {-week action plans for each topic } \\
\text { (instruction on what, where and when to do } \\
\text { the suggestions for behaviour change) }\end{array}$ & $\begin{array}{l}\text { Seventh grade } \\
\text { Fall } \\
\text { Fall } \\
\text { Winter/spring } \\
\text { Winter/spring } \\
\text { Winter/spring }\end{array}$ & $\begin{array}{l}\text { Increase awareness of; } \\
\text { Recommended intake and PA level } \\
\text { Own intake of FV, PA level and hours of screen time } \\
\text { Received personal advice about what and how to change }\end{array}$ \\
\hline \multirow[t]{3}{*}{ Home/parents } & $\begin{array}{l}\text { Fact sheets } \\
\text { Facts on targeted behaviours. Practical tasks/ } \\
\text { challenges for leisure time/weekends in } \\
\text { seventh grade }\end{array}$ & $\begin{array}{l}\text { Monthly-throughout the } \\
\text { intervention, one behaviour } \\
\text { per fact sheet }\end{array}$ & $\begin{array}{l}\text { To stimulate parents to evaluate and change the home } \\
\text { environment with regard to facilitating or regulating the } \\
\text { targeted behaviours }\end{array}$ \\
\hline & $\begin{array}{l}\text { Brochures/information sheets } \\
\text { Teachers were provided info sheets about the } \\
\text { FV break that they could use to inform } \\
\text { parents about these }\end{array}$ & Once & $\begin{array}{l}\text { To ensure that the fact sheets were read and discussed/applied } \\
\text { to the home environment }\end{array}$ \\
\hline & $\begin{array}{l}\text { Brochures: } \\
\text { 'Cutting FV' } \\
\text { 'Meals-a value worth fighting for'. Handed } \\
\text { out together with related fact sheets }\end{array}$ & Once & To provide knowledge and inspiration. \\
\hline \multirow[t]{4}{*}{ School-wide } & $\begin{array}{l}\text { Kick-off meetings at each school:Teacher } \\
\text { manuals presented, practical activities tested, } \\
\text { material partially provided }\end{array}$ & $\begin{array}{l}\text { Once a year-sixth and } \\
\text { seventh grades (fall), } 2-3 \mathrm{~h} \\
\text { each time }\end{array}$ & $\begin{array}{l}\text { To inform the school management, teachers, school nurse and } \\
\text { parent committees about the project and establish/inform the } \\
\text { grade level teachers as the 'HEIA team' at school }\end{array}$ \\
\hline & $\begin{array}{l}\text { Inspirational courses for PE teachers } \\
\text { SPARK ideas/principles }\end{array}$ & $\begin{array}{l}\text { Once a year-sixth and } \\
\text { seventh grades (fall), } 6 \mathrm{~h} \\
\text { each time }\end{array}$ & $\begin{array}{l}\text { Teacher training for PE teachers; methods/activities to increase } \\
\text { activity time, enjoyment and self-efficacy for all students during } \\
\text { PE classes }\end{array}$ \\
\hline & $\begin{array}{l}\text { Resource box for school management } \\
\text { Offer to order free toolbox for cutting and } \\
\text { selling FV }\end{array}$ & Optional & $\begin{array}{l}\text { Focus on healthy food/drinks offered in school/during school } \\
\text { events }\end{array}$ \\
\hline & $\begin{array}{l}\text { Committee meetings } \\
\text { Meetings with school environment groups/ } \\
\text { parent committees }\end{array}$ & Optional & $\begin{array}{l}\text { Aimed to stimulate easy-to-do changes on the school grounds } \\
\text { that could stimulate activity (booklet/ideas provided). Increase } \\
\text { awareness of healthy foods and beverages }\end{array}$ \\
\hline $\begin{array}{l}\text { Leisure time activities } \\
\left(\mathrm{NGO}^{\prime} \mathrm{s}\right)^{*}\end{array}$ & $\begin{array}{l}\text { Information folder and offer to receive a } \\
\text { resource box with equipment for cutting and } \\
\text { selling FV }\end{array}$ & Seventh grade (fall) & $\begin{array}{l}\text { Create awareness about leisure time activity leaders as role } \\
\text { models for dietary habits, to reflect upon availability of food/ } \\
\text { drinks during practices and events (ie, tournaments, weekend } \\
\text { training sessions, etc) }\end{array}$ \\
\hline
\end{tabular}

${ }^{*}$ Not successfully implemented.

FV, fruits and vegetables; HEIA, HEalth In Adolescents; NGO, non-governmental organisation; PE, physical education. 
among 114 children; ${ }^{16}$ all tests had a reasonable reproducibility (intra-class correlation (ICC) and Pearson's R 0.76-0.99, $\mathrm{p}<0.001$, except voice change (boys only) ICC $0.36, \mathrm{p}<0.006$ ).

\section{Demographic characteristics}

On the informed consent, parents reported their educational level. Parental education was categorised into three levels: $<12$ years (low), 13-16 years (medium) and >16 years (high).

If both parents provided level of education, we included the parent with the highest level of education in our analyses; we otherwise used data provided by either parent.

\section{Data preparation and statistics}

To address the clustered effects of schools as the unit of recruitment while children were the unit of analysis, we conducted a Linear Mixed Model Procedure (analyses available upon request). Both Tabachnick and Fidell and Heck et al state that if the ICC is small when quantifying the degree of clustering $(<5 \%)$, there is no meaningful difference among groups and the data may be analysed at the individual level. ${ }^{22} 23$ As only $2 \%$ of the variance in BMI and WC was explained by group, we did not adjust for clustering in our analysis. ${ }^{22} 23$

Baseline differences between the intervention and control groups were tested with independent sample $\mathrm{t}$ tests and a $\chi^{2}$ test. Drop-out analyses were done likewise. The effect of the intervention was determined using one-way analysis of covariance (ANCOVA) with the postintervention value for the outcomes as the dependent variables (continuous variables), baseline values of the outcomes as covariates and group (intervention vs control) as the independent variable. The same technique was used for categorical outcomes using logistic regressions. Interaction effects by gender, pubertal status and parental educational level were tested in separate analyses as a second step using two-way ANCOVA/logistic regressions with the interaction terms as covariates. The significance level of the interaction tests was set to $\mathrm{p}<0.1$. Significant interactions were explored by rerunning the analyses stratified by the moderator.
The significance level of the main analyses was set to $\mathrm{p}<0.05$. Data were analysed using the IBM SPSS Statistics V.18 (IBM Corp., New York, New York, USA).

\section{RESULTS}

Only 4\% of children dropped out of the study and attrition was equal between the intervention $(n=17)$ and control $(n=35)$ groups. Drop-out analyses showed that the participants lost to follow-up $(\mathrm{n}=52)$ weighed more $(42.8$ vs $39.7 \mathrm{~kg}, \mathrm{p}=0.01)$ and had a higher BMI (19.2 vs $\left.17.9 \mathrm{~kg} / \mathrm{m}^{2}, \mathrm{p}=0.01\right)$ and $\mathrm{BMIz}$ $(0.55$ vs $0.10, p=0.003)$ than the investigated sample $(n=1324)$. No other differences were detected.

There were no significant differences between the intervention and control groups at baseline with respect to age, gender, weight, height, pubertal status and parental education (table 2), as well as for body composition estimates. Table 2 also shows baseline characteristics by gender for descriptive purposes.

For the total sample, there were no significant intervention effects on any of the body composition measures outlined in table 3, or for weight status: OR 1.6 (95\% CI 0.9 to 2.7), $\mathrm{p}=0.1$. Gender was identified as a moderator of the intervention effects on BMI $(p=0.02)$, BMIz $(p<0.01)$, WC $(p=0.05)$ and WTHR $(p=0.05)$. The effect on BMI was also moderated by parental education $(p=0.04)$; similar was the effect on WTHR $(p=0.06)$. No moderating effects of pubertal status were detected (data not shown). After stratification, there was a significant intervention effect on BMI for girls; girls in the intervention group increased less on BMI compared with the control group. No such effect was seen for boys. Similarly, an intervention effect was seen on BMIz for girls but not for boys. For WC and WTHR, there was no significant intervention effect for either gender after stratification (table 3). Furthermore, a beneficial intervention effect on BMI among the participants of parents with high education was found, but no effect was detected among participants of parents with medium or low education. For WTHR, a negative effect was found among participants of parents with low education.

Table 2 Characteristics at baseline for the HEIA study intervention and control groups and by gender

\begin{tabular}{|c|c|c|c|c|c|}
\hline & Control $(n=859)$ & Intervention $(n=465)$ & p Value* & Girls $(n=643)$ & Boys $(n=681)$ \\
\hline Age (years) & $11.2(0.3)$ & $11.2(0.3)$ & 0.59 & $11.2(0.3)$ & $11.2(0.3)$ \\
\hline Girls (\% (n)) & 48 (409) & $50(234)$ & 0.35 & & \\
\hline Weight (kg) & $39.8(7.8)$ & $39.5(7.6)$ & 0.46 & $40.2(7.9)$ & $39.2(7.6)$ \\
\hline Height (cm) & $148.5(6.8)$ & $148.6(6.7)$ & 0.93 & $149.0(7.2)$ & $148.2(6.4)$ \\
\hline Puberty scale score (\% (n)) & & & 0.38 & & \\
\hline Prepubertal & $21.5(174)$ & $19.4(85)$ & & $9.4(59)$ & $32.2(200)$ \\
\hline Early pubertal & $35.9(291)$ & 33.9 (149) & & $19.4(122)$ & $51.1(318)$ \\
\hline Mid-late-postpubertal & 42.7 (346) & $46.7(205)$ & & $71.2(447)$ & 16.7 (104) \\
\hline Parental education (years) (\% (n)) & & & 0.10 & & \\
\hline$<12$ & 30.9 (259) & $26.7(120)$ & & $29.9(188)$ & $28.9(191)$ \\
\hline $13-16$ & $36.2(304)$ & $36.7(165)$ & & $33.0(207)$ & $39.6(262)$ \\
\hline$>16$ & $32.9(276)$ & $36.7(165)$ & & $37.1(233)$ & 31.5 (208) \\
\hline BMI $\left(\mathrm{kg} / \mathrm{m}^{2}\right)$ & $17.9(2.6)$ & $17.8(2.5)$ & 0.29 & $18.0(2.6)$ & $17.8(2.6)$ \\
\hline BMI z-score & $0.13(1.08)$ & $0.06(1.03)$ & 0.29 & $0.08(1.01)$ & $0.13(1.11)$ \\
\hline Overweight/obesity† (\% (n)) & $14(120)$ & $11(50)$ & 0.10 & $13(85)$ & $12(85)$ \\
\hline Waist circumference $(\mathrm{cm})$ & $63.3(6.5)$ & $62.7(6.1)$ & 0.10 & $62.2(6.2)$ & $63.9(6.5)$ \\
\hline Waist-to-height ratio (WTHR) & $0.43(0.04)$ & $0.42(0.04)$ & 0.06 & $0.42(0.04)$ & $0.43(0.04)$ \\
\hline
\end{tabular}

*Differences between intervention and control groups were tested by student $t$ test $/ \chi^{2}$ test.

†As defined by the International Obesity Task Force's cut-offs for overweight/obesity at ages from 10.5 to 12.5 (weight status)

BMI, body mass index; HEIA, HEalth In Adolescents. 
Table 3 Intervention effects of the HEIA study on anthropometric outcomes after 20 months; total sample and by gender and parental education

\begin{tabular}{|c|c|c|c|}
\hline & Control $(n=859)$ & Intervention $(n=465)$ & \\
\hline & Mean $(95 \% \mathrm{Cl})$ & Mean $(95 \% \mathrm{Cl})$ & p Value \\
\hline BMI, total sample & 18.9 (18.8 to 18.9$)$ & 18.8 (18.7 to 18.9$)$ & 0.501 \\
\hline \multicolumn{4}{|l|}{ Gender } \\
\hline Girls & 19.2 (19.1 to 19.3$)$ & 19.0 (18.8 to 19.3$)$ & 0.024 \\
\hline Boys & 18.5 (18.4 to 18.6$)$ & 18.6 (18.5 to 18.7$)$ & 0.306 \\
\hline \multicolumn{4}{|l|}{ Parental education } \\
\hline Low & 19.3 (19.1 to 19.4$)$ & 19.4 (19.2 to 19.7$)$ & 0.189 \\
\hline Medium & $18.7(18.6,18.8)$ & 18.7 (18.5 to 18.8$)$ & 0.742 \\
\hline High & 18.6 (18.5 to 18.8$)$ & 18.4 (18.2 to 18.6$)$ & 0.027 \\
\hline BMIz, total sample & $-0.01(-0.04$ to 0.02$)$ & $-0.04(-0.09$ to 0.00$)$ & 0.227 \\
\hline \multicolumn{4}{|l|}{ Gender } \\
\hline Girls & $0.03(-0.01$ to 0.08$)$ & $-0.8(-0.14$ to -0.02$)$ & 0.003 \\
\hline Boys & $-0.05(-0.09$ to -0.00$)$ & $-0.01(-0.07$ to 0.05$)$ & 0.322 \\
\hline WC, total sample & 66.2 (66.0 to 66.5 ) & 66.4 (66.0 to 66.7) & 0.502 \\
\hline \multicolumn{4}{|l|}{ Gender } \\
\hline Girls & 66.0 (66.0 to 66.3$)$ & 65.7 (65.3 to 66.1$)$ & 0.279 \\
\hline Boys & 66.4 (66.1 to 67.5$)$ & $67.0(66.5$ to 67.5$)$ & 0.089 \\
\hline WTHR, total sample & $0.416(0.415$ to 0.418$)$ & $0.418(0.415$ to 0.420$)$ & 0.412 \\
\hline \multicolumn{4}{|l|}{ Gender } \\
\hline Girls & $0.414(0.412$ to 0.416$)$ & $0.413(0.416$ to 0.421$)$ & 0.344 \\
\hline Boys & 0.419 (0.416 to 0.421$)$ & 0.422 (0.419 to 0.425$)$ & 0.089 \\
\hline \multicolumn{4}{|l|}{ Parental education } \\
\hline Low & $0.420(0.417$ to 0.423$)$ & $0.426(0.422$ to 0.430$)$ & 0.020 \\
\hline Medium & 0.417 (0.414 to 0.419$)$ & $0.415(0.412$ to 0.419$)$ & 0.484 \\
\hline High & $0.413(0.410$ to 0.416$)$ & $0.413(0.410$ to 0.416$)$ & 0.978 \\
\hline
\end{tabular}

Intervention effects determined by analysis of covariance adjusted for baseline value. BMI, body mass index; BMIz, BMI-for-age z-score; HEIA, HEalth in Adolescents;WC, waist circumference; WTHR, waist-to-height-ratio. Bold signifies $p<0.05$.

\section{DISCUSSION}

The HEIA study had a beneficial effect on BMI and BMIz in girls, but not in boys. A beneficial effect on BMI was seen among participants of parents with higher education. However, a negative intervention effect on WTHR was seen among participants of parents reporting low education.

\section{Effect of the intervention on BMI}

One reason for the lack of overall effect on BMI for both boys and girls can be the inadequate dose received of intervention components. Unpublished process evaluation data indicate that the level of implementation of the components decreased from midway to postintervention, thus reducing both the reach and dose received by the participants. Furthermore, since low cost and high applicability of the intervention activities in the public school system were given high priority, this may also have limited the dose received on each of the targeted behaviours. Moreover, the diet and activity behaviours that were promoted in the intervention, separately or in combination, may not have been sufficient to affect estimates of body composition to a greater magnitude. ${ }^{3}$ The length of the intervention, being almost two academic years, can be considered relatively long compared with similar school-based interventions. ${ }^{45} 24$ Sufficiently intense intervention (daily expert-led physical education) and adequate duration ( 1 year) were two strengths that were pointed out in the successful KISS study, which managed to favourably affect estimates of body composition in first and fifth grade schoolchildren. ${ }^{24}$ Additionally, both the control group and the intervention group in the present study increased their total physical activity significantly during the intervention. ${ }^{15}$ This was unexpected as a decline in physical activity with increasing age has repeatedly been documented between the ages 9 and $15 .^{25-27}$ We cannot rule out that the control schools have initiated their own healthpromoting initiatives, even if allocated to the control arm of the study. For ethical reasons, we made no attempt to prevent this. The lack of overall intervention effects can also be due to the limited potential for change, as the majority of participants in this study were of normal weight at baseline. ${ }^{5}$

\section{Effect of the intervention on secondary objectives}

We have previously reported that gender moderated the effect of the HEIA intervention on dietary behaviours, sedentary behaviours and physical activity. ${ }^{13} 14$ The effect of the intervention was greater for girls than for boys on most of the outcomes we investigated.

This can have several explanations. Four female researchers developed the intervention and assisted the implementation. The majority of teachers involved in this project were women. Unintentionally, the intervention components may therefore have been better adapted and delivered to girls than to boys. The earlier demonstrated intervention effects on behaviours in girls but not in boys may partly explain why the intervention was effective on BMI and BMIz among girls only. ${ }^{14}{ }^{15}$ It is possible that boys did not change their physical activity level as much as girls because of higher baseline values and, consequently, had a smaller potential for change. Furthermore, the issues addressed in the study may be of greater interest to girls, or girls may be more conscientious regarding the intervention components than boys. We appreciate the results showing that the intervention reached and affected girls. However, we also acknowledge that the intervention failed to affect the same outcomes in boys. Similarly, the American 'Planet Health' study significantly reduced the prevalence of obesity in 12-year-old girls by promotion of physical activity, modification of dietary intake and reduction of sedentary behaviours, but found no effect on boys. $^{28}$ On the other hand, another American intervention study targeting environment, policy and social marketing (M-SPAN) showed a significant reduction in BMI in 11-year-old to 13-year-old boys over two school years, but not in girls. ${ }^{29}$ A systematic review of school-based interventions that focused on changing dietary intake and physical activity to prevent childhood obesity concluded that such interventions may be more effective for younger children and girls. ${ }^{30}$ The authors suggested that children aged 10-14 years may respond differently by genders to different intervention elements.

The present study demonstrated a beneficial intervention effect on participants having parents with high education, and a negative intervention effect on participants in the lowest parental education group with respect to WTHR. While acknowledging that we failed to positively reach participants of parents with low education, the reason is not readily explainable. In an attempt to explain social differences in fruit and vegetable consumption among Norwegian schoolchildren, Bere et $a l^{31}$ found that children with lower educated parents had less access to fruits and vegetables than children with higher educated parents, and hypothesised that cost, greater knowledge, health considerations and greater support from family and friends could be the reasons for this difference. The results are in line with earlier findings, which describe a social gradient in the problem of adolescent overweight and obesity, ${ }^{32-35}$ and which show that population-based intervention efforts seem to reach 
participants from different socioeconomic backgrounds differently and may contribute to increased health inequalities. ${ }^{1} 36$

In this paper, we chose to include multiple estimates of body composition as called for ${ }^{4}$ although BMI was the main outcome variable in the study. It is noteworthy that relatively closely related outcomes, that is, BMI and WTHR, gave different results regarding intervention effects. All the investigated outcomes are descriptions of body composition and more equal effects could have been expected. The results suggest that there are differences in how the intervention affects these measures. The power analyses were calculated to detect differences between groups for BMI; the other investigated anthropometric outcomes may have required a larger sample size to detect intervention effects.

Regarding effect size, all the significant effect sizes were classified as small. The highest explained variance was only $1.4 \%$ in girls' BMIz and WTHR in the lowest parental education group. This means that most of the participants' estimates of body composition development during the trial were explained by other factors, and thus the importance of the intervention effects may be limited. However, obtaining small but beneficial findings such as this can be important for public health if implemented on a larger scale and with a longer duration.

\section{Strengths and limitations}

The strengths of the study include the systematic development of the intervention and the study design, which were based on the current recommendations and best practice. ${ }^{2} 2937$ Other strengths were the large number of participants from a narrow age group. Furthermore, the multicomponent intervention lasting 20 months was designed to be feasible to implement within the school system and not financially demanding. Also, the anthropometric measures were objectively assessed, selfreported pubertal maturation was included and parental education was reported by a parent for nearly the full sample.

We acknowledge that our study has limitations. A possible selection bias might be present because a rather large proportion of invited schools declined to take part in the study. Recruiting schools in Norway to extracurricular projects has become a challenging undertaking over the past decade, as curricular and administrative demands on schools have increased substantially. In addition, weighing of children is a controversial issue in Norway and has been debated in the national media repeatedly. However, attrition analyses showed no differences between the participating schools and schools which declined to participate in terms of the number of students in the sixth grade and the overall size. $^{38}$ The drop-out analyses showed that participants lost to follow-up had a higher BMI and indicate that we lost participants that we intended to reach. A possible reason for this attrition could be resistance to assessment of anthropometrics in light clothing or underwear only. This was discovered as the main reason for adolescents to refuse participation in the anthropometric measurement in a Dutch school-based weight gain prevention programme. ${ }^{39}$ However, the drop-out rate was small and equal in both groups, and no further differences were detected. Also, when investigating the intervention effects of a multicomponent intervention, it is not possible to sort out the effects of the different components. Finally, as the sample was recruited from a limited geographic area, this could reduce the generalisability of our findings. However, the objectively measured height, weight and total physical activity from the participants in this study fall adequately between the measures of 9 -year-olds and 15 -year -olds in a nationally representative sample. ${ }^{40}$

\section{CONCLUSION}

We demonstrated that a 20-month comprehensive multicomponent school-based intervention designed to increase physical activity, reduce sedentary time and stimulate a healthy diet successfully decreased BMI and BMIz among girls, but not boys.

The intervention had a beneficial effect on BMI among children of parents with higher education, but not among children of parents with lower education. Future interventions should be aware of differences in how the intervention affects genders and socioeconomic groups, and should adequately address this issue to eliminate chances of increasing inequalities in health with regard to obesity development.

\section{What this study adds}

A multicomponent school-based obesity prevention intervention produced significant positive effects on estimates of body composition among participating adolescent girls, but not among the boys.

- The intervention gave positive results for participants having parents with higher education, while negative effects were seen among those with parents having lower education. The risk that interventions contribute to increase social inequalities in health should be given attention in future intervention studies.

Acknowledgements We sincerely thank the participants, their parents and teachers and the project staff.

Contributors All authors are responsible for the reported research. MG worked on the statistical analyses, wrote the first draft and made the greatest contribution to the manuscript. NL was the project coordinator and participated in all parts of the work. K-IK, LFA, YO and SAA were mainly involved in designing the study while $I H B, M B$ and $M G$ were mainly responsible for planning and conducting the data collections and the intervention. K-IK initiated the study. All authors provided critical revision of the manuscript and read and approved the final manuscript.

Funding The study HEalth In Adolescents (HEIA) was funded by the Norwegian Research Council (grant number 175323/V50) with supplementary funds from the Throne Holst Nutrition Research Foundation, University of Oslo and the Norwegian School of Sport Science.

\section{Competing interests None.}

\section{Patient consent Obtained.}

Ethics approval Regional Committees for Medical Research Ethics, Norway. Provenance and peer review Not commissioned; externally peer reviewed.

Open Access This is an Open Access article distributed in accordance with the Creative Commons Attribution Non Commercial (CC BY-NC 3.0) license, which permits others to distribute, remix, adapt, build upon this work non-commercially, and license their derivative works on different terms, provided the original work is properly cited and the use is non-commercial. See: http://creativecommons.org/ licenses/by-nc/3.0/

\section{REFERENCES}

1 Waters E, De Silva-Sanigorski A, Hall BJ, et al. Interventions for preventing obesity in children. Cochrane Database Syst Rev 2011;12:CD001871.

2 Summerbell $C D$, Waters $E$, Edmunds $L D$, et al. Interventions for preventing obesity in children. Cochrane Database Syst Rev 2005;3:CD001871.

3 Metcalf $B$, Henley W, Wilkin T. Effectiveness of intervention on physical activity of children: systematic review and meta-analysis of controlled trials with objectively measured outcomes (EarlyBird 54). BMJ 2012;345:e5888.

4 Gonzalez-Suarez C, Worley A, Grimmer-Somers K, et al. School-based interventions on childhood obesity: a meta-analysis. Am J Prev Med 2009;37:418-27.

5 Silveira JA, Taddei JA, Guerra PH, et al. Effectiveness of school-based nutrition education interventions to prevent and reduce excessive weight gain in children and adolescents: a systematic review. J Pediatr (Rio J) 2011:87:382-92. 
6 Wareham NJ, Van Sluijs EM, Ekelund U. Physical activity and obesity prevention: a review of the current evidence. Proc Nutr Soc 2005;64:229-47.

7 Inokuchi M, Matsuo N, Takayama Jl, et al. BMl z-score is the optimal measure of annual adiposity change in elementary school children. Ann Hum Biol 2011;38:747-51.

8 Harris KC, Kuramoto LK, Schulzer M, et al. Effect of school-based physical activity interventions on body mass index in children: a meta-analysis. CMAJ 2009;180:719-26.

9 Cole TJ, Faith MS, Pietrobelli A, et al. What is the best measure of adiposity change in growing children: BMI, BMI \%, BMI z-score or BMI centile? Eur J Clin Nutr 2005:59:419-25

10 Yildirim M, Van Stralen MM, Chinapaw MJ, et al. For whom and under what circumstances do school-based energy balance behavior interventions work? Systematic review on moderators. Int J Pediatr Obes 2011;6:e46-57.

11 Khambalia AZ, Dickinson S, Hardy LL, et al. A synthesis of existing systematic reviews and meta-analyses of school-based behavioural interventions for controlling and preventing obesity. Obes Rev 2012;13:214-33.

12 Kamath CC, Vickers KS, Ehrlich A, et al. Clinical review: behavioral interventions to prevent childhood obesity: a systematic review and meta-analyses of randomized trials. J Clin Endocrinol Metab 2008;93:4606-15.

13 Bergh $\mathrm{IH}$, Bjelland $\mathrm{M}$, Grydeland $\mathrm{M}$, et al. Mid-way and post-intervention effects on potential determinants of physical activity and sedentary behavior, results of the HEIA study - a multicomponent school-based randomized trial. Int J Behav Nutr Phys Act 2012;9:63.

14 Bjelland $M$, Bergh $\mathrm{IH}$, Grydeland $\mathrm{M}$, et al. Changes in adolescents' intake of sugar-sweetened beverages and sedentary behaviour: results at 8 month mid-way assessment of the HEIA study - a comprehensive, multi-component school-based randomized trial. Int J Behav Nutr Phys Act 2011;8:63.

15 Grydeland M, Bergh IH, Bjelland M, et al. Intervention effects on physical activity: the HEIA study — a cluster randomized controlled trial. Int J Behav Nutr Phys Act 2013;10:17.

16 Lien $\mathrm{N}$, Bjelland $\mathrm{M}$, Bergh $\mathrm{IH}$, et al. Design of a 20-month comprehensive, multicomponent school-based randomised trial to promote healthy weight development among 11-13-year olds: the HEalth In Adolescents study. Scand J Public Health 2010;38:38-51.

17 Sim J, Wright C. Research in health care: concepts, designs and methods. Cheltenham: Stanley Thornes Ltd, 2000.

18 Sallis JF, McKenzie TL, Alcaraz JE, et al. Project SPARK. Effects of physical education on adiposity in children. Ann N Y Acad Sci 1993;699:127-36.

19 De Onis M, Onyango AW, Borghi E, et al. Development of a WHO growth reference for school-aged children and adolescents. Bull World Health Organ 2007:85:660-7.

20 Cole TJ, Bellizzi MC, Flegal KM, et al. Establishing a standard definition for child overweight and obesity worldwide: international survey. BMJ 2000:320:1240-3.

21 Carskadon MA, Acebo C. A self-administered rating scale for pubertal development. J Adolesc Health 1993:14:190-5.

22 Heck R, Thomas S, Tabata L. Multilevel and longitudinal modeling with IBM SPSS. New York, NY 10016: Routledge, 2010

23 Tabachnick BG, Fidell LS. Multilevel linear modeling. Using multivariate statistics. Boston: Pearson Education Inc, 2007.

24 Kriemler S, Zahner L, Schindler C, et al. Effect of school based physical activity programme (KISS) on fitness and adiposity in primary schoolchildren: cluster randomised controlled trial. BMJ 2010:340:c785
25 Kolle E, Steene-Johannessen J, Andersen LB, et al. Objectively assessed physical activity and aerobic fitness in a population-based sample of Norwegian 9- and 15-year-olds. Scand J Med Sci Sports 2010:20:e41-7.

26 Riddoch CJ, Bo AL, Wedderkopp N, et al. Physical activity levels and patterns of 9- and 15-yr-old European children. Med Sci Sports Exerc 2004;

36:86-92.

27 Haug E, Rasmussen M, Samdal O, et al. Overweight in school-aged children and its relationship with demographic and lifestyle factors: results from the WHO-Collaborative Health Behaviour in School-aged Children (HBSC) study. Int J Public Health 2009:54(Suppl 2):167-79.

28 Gortmaker SL, Peterson K, Wiecha J, et al. Reducing obesity via a school-based interdisciplinary intervention among youth: Planet Health. Arch Pediatr Adolesc Med 1999;153:409-18.

29 Sallis JF, McKenzie TL, Conway TL, et al. Environmental interventions for eating and physical activity: a randomized controlled trial in middle schools. Am J Prev Med 2003:24:209-17.

30 Brown T, Summerbell C. Systematic review of school-based interventions that focus on changing dietary intake and physical activity levels to prevent childhood obesity: an update to the obesity guidance produced by the National Institute for Health and Clinical Excellence. Obes Rev 2009;10:110-41.

31 Bere $\mathrm{E}$, Van LF, Klepp KI, et al. Why do parents' education level and income affect the amount of fruits and vegetables adolescents eat? Eur J Public Health 2008;18:611-15.

32 Groholt EK, Stigum H, Nordhagen R. Overweight and obesity among adolescents in Norway: cultural and socio-economic differences. J Public Health (Oxf) 2008;30:258-65.

33 Lien N, Kumar BN, Holmboe-Ottesen G, et al. Assessing social differences in overweight among 15- to 16-year-old ethnic Norwegians from Oslo by register data and adolescent self-reported measures of socio-economic status. Int J Obes (Lond) 2007:31:30-8.

34 Grydeland $\mathrm{M}$, Bergh $\mathrm{IH}$, Bjelland $\mathrm{M}$, et al. Correlates of weight status among Norwegian 11-year-olds: The HEIA study. BMC Public Health 2012:12:1053.

35 Brug J, Van Stralen MM, Te Velde SJ, et al. Differences in weight status and energy-balance related behaviors among schoolchildren across Europe: the ENERGY-project. PLOS ONE 2012;7:e34742.

36 Frohlich $\mathrm{KL}$, Potvin $\mathrm{L}$. Transcending the known in public health practice: the inequality paradox: the population approach and vulnerable populations. Am J Public Health 2008:98:216-21.

37 Doak CM, Visscher TL, Renders CM, et al. The prevention of overweight and obesity in children and adolescents: a review of interventions and programmes. Obes Rev 2006:7:111-36

38 Gebremariam MK, Andersen LF, Bjelland M, et al. Does the school food environment influence the dietary behaviours of Norwegian 11-year-olds? The HEIA study. Scand J Public Health 2012;40:491-7.

39 Singh AS, Chinapaw MJ, Brug J, et al. Process evaluation of a school-based weight gain prevention program: the Dutch Obesity Intervention in Teenagers (DOiT) Health Educ Res 2009;24:772-7.

40 The Norwegian Directorate of Health. Fysisk aktivitet blant 6-, 9-og 15-åringer $i$ Norge. Oslo, Norway: The Norwegian Directorate of Health, 2012. 